\title{
The BH3 mimetic S1 induces endoplasmic reticulum stress-associated apoptosis in cisplatin-resistant human ovarian cancer cells although it activates autophagy
}

\author{
NING LIU $^{1 *}$, YE XU $^{2 *}$, JI-TONG SUN ${ }^{1}$, JING SU$^{1}$, XI-YAN XIANG ${ }^{1}$, \\ HAO-WEI YI ${ }^{1}$, ZHI-CHAO ZHANG ${ }^{3}$ and LIAN-KUN SUN ${ }^{1}$ \\ ${ }^{1}$ Department of Pathophysiology, Norman Bethune College of Medicine, Jilin University, Changchun, Jilin 130021; \\ ${ }^{2}$ Medical Research Laboratory, Jilin Medical College, Jilin 132013; ${ }^{3}$ State Key Laboratory of Fine Chemicals, \\ School of Chemistry, Dalian University of Technology, Dalian, Liaoning 116012, P.R. China
}

Received April 25, 2013; Accepted May 20, 2013

DOI: 10.3892/or.2013.2771

\begin{abstract}
SKOV3/DDP human ovarian cancer cells have been shown to be resistant to cisplatin. Although the $\mathrm{BH} 3$ mimetic S1 induces cell death in several types of tumor cells, it is unclear whether it induces death in drug-resistant cells. Herein, we found that $\mathrm{S} 1$ induced endoplasmic reticulum (ER) stress-associated apoptosis in both SKOV3 and SKOV3/DDP cells. S1 activated autophagy at early time points in SKOV3/ DDP cells, and inhibition of autophagy increased ER stressassociated apoptosis. Collectively, our data indicate that autophagy plays a protective role, but it cannot protect against S1-induced cell death in cisplatin-resistant SKOV3/DDP cells.
\end{abstract}

\section{Introduction}

Currently, resistance to chemotherapy is a major issue in the clinical treatment of tumors. The mechanism of tumor resistance to chemotherapy is extremely complex, and high expression of anti-apoptotic protein Bcl-2 is considered to be a major reason why tumor cells escape from apoptosis (1-3). Bcl-2-specific inhibitors can increase the sensitivity of tumor cells to chemotherapeutics (4-7). Therefore, exploring the activity and mechanism of Bcl-2 inhibitors can provide new insights into the treatment of tumors, including drug-resistant tumors.

Bcl-2 is involved in not only the mitochondrial apoptotic pathway, but also in autophagy and endoplasmic reticulum

Correspondence to: Professor Lian-Kun Sun, Department of Pathophysiology, Norman Bethune College of Medicine, Jilin University, Changchun, Jilin 130021, P.R. China

E-mail:sunlk@jlu.edu.cn

*Contributed equally

Key words: BH3 mimetic, drug resistance, ER stress, autophagy ovarian cancer
(ER) stress. During tunicamycin- and thapsigargin-induced ER stress, Bcl-2 was found to mediate the stability of the ER membrane and to be involved in ER stress-mediated apoptosis $(8,9)$. HA14-1, a Bcl-2 inhibitor, significantly increased proteasome inhibitor bortezomib-induced cell death by increasing JNK- and caspase-4-mediated ER stress-induced apoptosis (10). In addition, Bcl-2, which is located at the ER, binds to Beclin-1 containing a BH3 region, thereby inhibiting Beclin-1-dependent autophagy (11-13). A natural BH3 mimetic was found to release Beclin-1 and then induce autophagy through inhibition of Bcl-2 or Bcl-XL expression (14). Although ER stress and autophagy are two independent response mechanisms in cells, there is an important link between them. Inhibition of autophagy can enhance chemotherapeutic effects by upregulating ER stress-mediated apoptosis $(15,16)$.

$\mathrm{S} 1$, a Bcl-2-specific inhibitor, is a $\mathrm{BH} 3$-only protein mimetic (17). S1 has been proven to induce apoptosis of liver cancer cells and breast cancer cells via the mitochondrial pathway by interfering with the interactions between Bcl-2/Bax and $\mathrm{Mcl}-1 / \mathrm{Bak}$, and thus exhibits antitumor activity $(18,19)$. Moreover, S1 was shown to induce autophagy and ER stress in human glioma cells (20).

In the present study, S1 was found to inhibit the survival of SKOV3 ovarian cancer cells and their related cisplatinresistant SKOV-3/DDP cells, and a significantly higher level of autophagy was detected in S1-treated SKOV3/DDP cells compared with SKOV3 cells. We also observed that activation of autophagy delayed S1-mediated apoptosis in SKOV3/DDP cells at early time points. In addition, we found that although S1 activated autophagy, it induced apoptosis in drug-resistant tumor cells via the ER stress-mediated caspase-4 pathway. Therefore, Bcl-2 family protein targeted therapy is a promising therapeutic strategy for the treatment of human ovarian cancer.

\section{Materials and methods}

Cell culture. SKOV3 human ovarian cancer cells and their related cisplatin-resistant SKOV3/DDP cells were obtained from the Chinese Academy of Medical Sciences and Peking 
Union Medical College. Both cell lines were cultured at $37^{\circ} \mathrm{C}$ under $5 \% \mathrm{CO}_{2}$ in Roswell Park Memorial Institute (RPMI)-1640 culture medium (Gibco, Carlsbad, CA, USA) supplemented with $10 \%$ fetal bovine serum (Invitrogen, Carlsbad, CA, USA). In addition, SKOV3/DDP cells were maintained in RPMI-1640 medium supplemented with $10 \%$ fetal bovine serum plus $1 \mu \mathrm{g} / \mathrm{ml}$ cisplatin (Sigma-Aldrich, St. Louis, MO, USA) to maintain their resistance.

Cell viability assays. SKOV3 and SKOV3/DDP cells were plated in 96-multi-well plates at $1 \times 10^{4}$ cells/well $24 \mathrm{~h}$ before treatment. The cells were then treated with increasing concentrations of S1 for 12 or $24 \mathrm{~h}$, or with $10 \mu \mathrm{M} \mathrm{S} 1$ for different time periods. Each treatment was repeated in three wells. The cell viability was assessed using the MTT colorimetric assay. Briefly, MTT (3-[4,5-dimethylthiazol-2-yl]-2,5-diphenyltetrazolium bromide) (10 $\mu \mathrm{l} ; 5 \mathrm{mg} / \mathrm{ml}$ in PBS; Sigma-Aldrich) was added and incubated for $4 \mathrm{~h}$. Subsequently, $150 \mu \mathrm{l}$ of dimethyl sulfoxide was added to dissolve the formazan crystals. After shaking for $10 \mathrm{~min}$, the absorbance values were measured at a wavelength of $570 \mathrm{~nm}$ using a microplate reader (Molecular Devices, Sunnyvale, CA, USA).

Western blot analysis. Whole-cell proteins were extracted from the human ovarian cancer cells using RIPA buffer. After two sonications for $10 \mathrm{sec}$ each on ice, the cells were lysed at $4^{\circ} \mathrm{C}$ for $45 \mathrm{~min}$. The cell lysates were centrifuged at $3,000 \mathrm{x} \mathrm{g}$ for $15 \mathrm{~min}$, and the protein concentrations were determined using a protein assay kit (Bio-Rad Laboratories Hercules, CA, USA). For western blot analysis, equivalent amounts of proteins $(30-90 \mu \mathrm{g})$ were separated by $12 \%$ SDS-polyacrylamide gel electrophoresis and transferred onto nitrocellulose membranes (Whatman, Maidstone, UK). The membranes were blocked with 5\% non-fat dry milk in buffer (10 mM Tris- $\mathrm{HCl} \mathrm{pH} 7.6,100 \mathrm{mM} \mathrm{NaCl}$ and $0.1 \%$ Tween-20) for $1 \mathrm{~h}$ at room temperature and then incubated with the relevant primary antibody overnight at $4^{\circ} \mathrm{C}$. The anti-PDI, anti-Beclin-1, anti-GRP78, anti-caspase-4, anti-JNK and antip-JNK antibodies (all used at a 1:200 dilution) were obtained from Santa Cruz Biotechnology (Santa Cruz, CA, USA). The anti- $\beta$-actin antibody (1:1,000 dilution) was obtained from Epitomics Inc. (Burlingame, CA, USA). The anti-LC3 antibody (1:500 dilution) was obtained from Abcam Hong Kong Ltd. (Hong Kong, China). On the following day, the membranes were incubated with a horseradish peroxidase-conjugated secondary antibody (Thermo Fisher Scientific, Waltham, MA, USA) at a 1:2,000 dilution for $1 \mathrm{~h}$ at room temperature. The immunoreactive bands were visualized by a diaminobenzidine (Sigma) coloration method. The reactive bands were measured with a Tanon GIS gel imager system, and the protein levels were quantified by densitometry using Quantity One software (Bio-Rad Laboratories).

Immunofluorescence staining and confocal laser microscopy. Cells were seeded onto coverslips in 24-well plates at a density of $5 \times 10^{4}$ cells/well $24 \mathrm{~h}$ before treatment. After exposure to $10 \mu \mathrm{M} \mathrm{S} 1$ for 0 or $24 \mathrm{~h}$, the cells were fixed with $4 \%$ paraformaldehyde for $30 \mathrm{~min}$, stained with the nuclear stain Hoechst 33342 (2 $\mu \mathrm{g} / \mathrm{ml}$; Sigma-Aldrich) for $2 \mathrm{~min}$, washed with PBS, and examined using an FV1000 confocal laser microscope (Olympus, Tokyo, Japan) to reveal the chromatin condensation.

The expression levels of microtubule-associated protein light chain 3 (LC3) and protein disulfide isomerase (PDI) were examined by an indirect immunofluorescence method. Cells were cultured on coverslips overnight, treated with $10 \mu \mathrm{M}$ S1 for different time periods, and fixed with $4 \%$ paraformaldehyde for $30 \mathrm{~min}$. After permeabilization with $0.1 \%$ Triton X-100 for $5 \mathrm{~min}$, the cells were blocked with bovine serum albumin for $30 \mathrm{~min}$, and incubated with a primary antibody against LC3 or PDI (1:100 dilution) overnight at $4^{\circ} \mathrm{C}$. On the following day, the cells were incubated with FITC/Texas Red-conjugated secondary antibodies (1:400 dilution; Santa Cruz Biotechnology) for $1 \mathrm{~h}$, stained with Hoechst $33342(2 \mu \mathrm{g} / \mathrm{ml})$ for $2 \mathrm{~min}$, washed with PBS three times, and examined using the Olympus FV1000 confocal laser microscope.

Statistical analysis. The data are representative of three independent experiments performed as triplicate determinations. Statistical analyses of the data were performed by one-way ANOVA. The Tukey post-hoc test was used to determine the significance of all pairwise comparisons of interest. Values of $\mathrm{P}<0.05$ were considered to indicate statistically significant differences.

\section{Results}

S1 inhibits the viability of SKOV3 and SKOV3/DDP cells. We treated cisplatin-sensitive SKOV3 and cisplatin-resistant SKOV3/DDP cells with increasing doses of S1 for 12 or $24 \mathrm{~h}$, and examined the growth inhibition using MTT assays. We found that $\mathrm{S} 1$ inhibited the viability of both cell lines (Fig. 1A and B). Based on the MTT assay results, we examined the apoptotic chromatin condensation by Hoechst 33342 staining and confocal microscopy. Compared with the control cells, S1 induced apoptotic chromatin in SKOV3 and SKOV3/DDP cells (Fig. 1C). After treatment with $10 \mu \mathrm{M} \mathrm{S1}$ for different time periods, it was interesting to note that SKOV3 cells were more sensitive to S1 than SKOV3/DDP cells at early time points (2 or $4 \mathrm{~h}$ ) (Fig. 1D), but in the end there was no difference in cell viability. These findings demonstrate that $\mathrm{S} 1$ has time- and dose-dependent effects on SKOV3 and SKOV3/DDP cells, and that SKOV3 cells are more sensitive at early time points.

S1 induces ER stress in SKOV3 and SKOV3/DDP cells. To evaluate whether $\mathrm{S} 1$ induces ER stress, we examined the expression of PDI, an ER-specific protein that accumulates under ER stress (21). Using confocal microscopy, we observed that PDI began to accumulate after $4 \mathrm{~h}$ in S1-treated SKOV3 cells, but only at $8 \mathrm{~h}$ in S1-treated SKOV3/DDP cells (Fig. 2A). By conducting western blot analysis, we found that the expression levels of PDI and Grp78, an ER chaperone protein (22), were upregulated at 4,8 and $12 \mathrm{~h}$ in SKOV3 cells, but at 8 and $12 \mathrm{~h}$ in SKOV3/DDP cells (Fig. 2B and C). To demonstrate that PDI accumulation was ER stress-dependent, we treated cells with tauroursodeoxycholic acid (TUDCA), a known inhibitor of ER stress $(23,24)$. As shown in Fig. 2D, PDI accumulation was downregulated at $12 \mathrm{~h}$ in both cell lines treated with S1 plus TUDCA, compared with cells treated with S1 alone. 
A

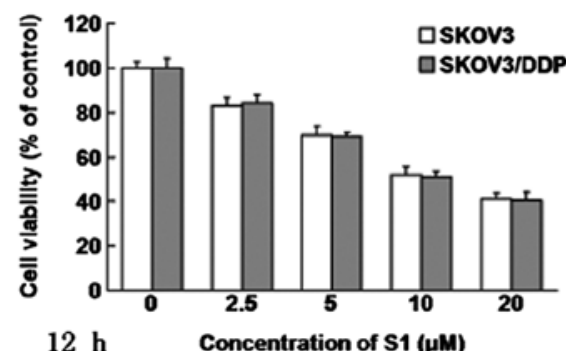

C
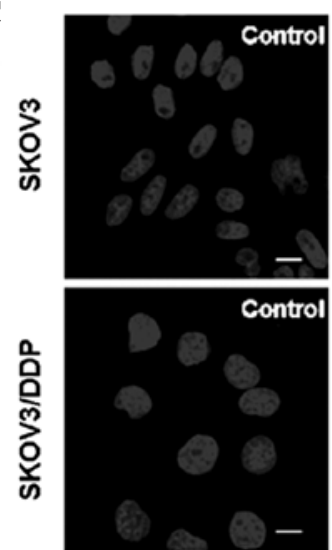
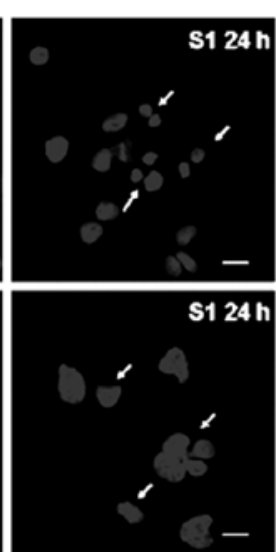

B

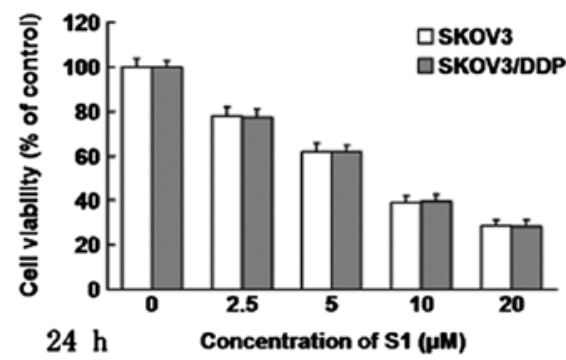

D

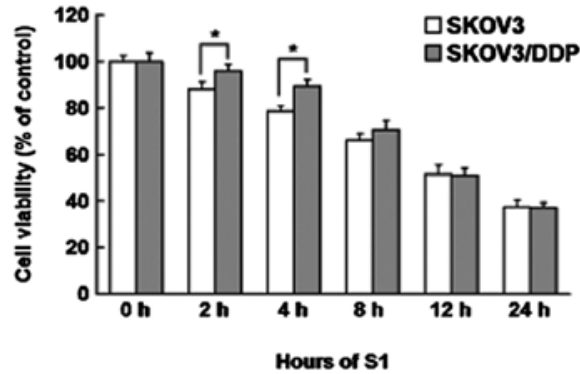

Figure 1. S1 affects viability and induces apoptosis in SKOV3 and SKOV3/DDP cells. (A and B) SKOV3 and SKOV3/DDP cells were treated with varying doses of S1 for 12 or $24 \mathrm{~h}$. Cell viability was determined by the MTT assay. Data are presented as means $\pm \mathrm{SD}(\mathrm{n}=3)$. (C) Cells were treated with $10 \mu \mathrm{M} \mathrm{S1}$ for 0 or $24 \mathrm{~h}$, and then stained with Hoechst 33342. The cell morphology was observed by confocal microscopy (bar, $10 \mu \mathrm{m}$; arrows, apoptotic cells). (D) Cells were treated with $10 \mu \mathrm{M} \mathrm{S1}$ for $0,2,4,8,12$ or $24 \mathrm{~h}$. Cell viability was determined by the MTT assay. Data are presented as means $\pm \mathrm{SD}(\mathrm{n}=3)$. ${ }^{*} \mathrm{P}<0.05$.

A
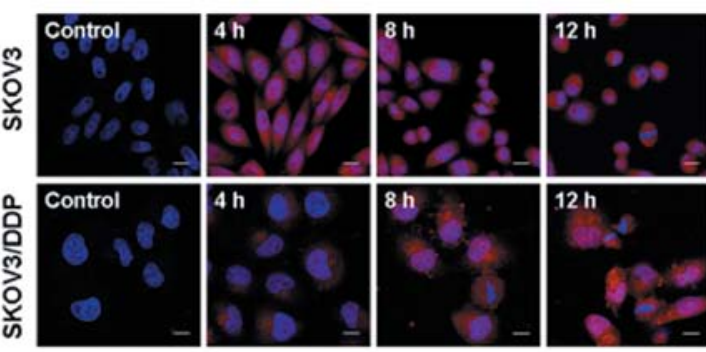

$\mathbf{C}$

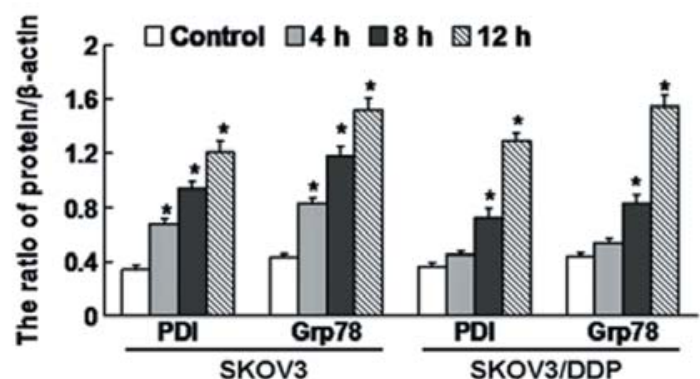

B

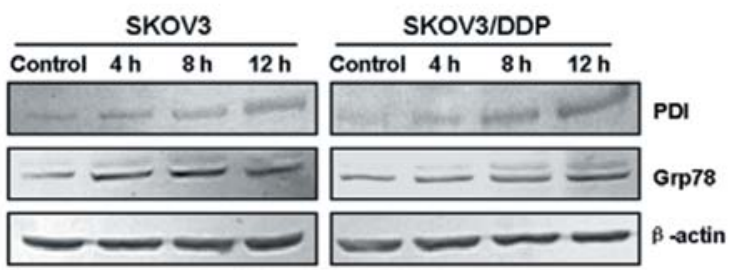

D
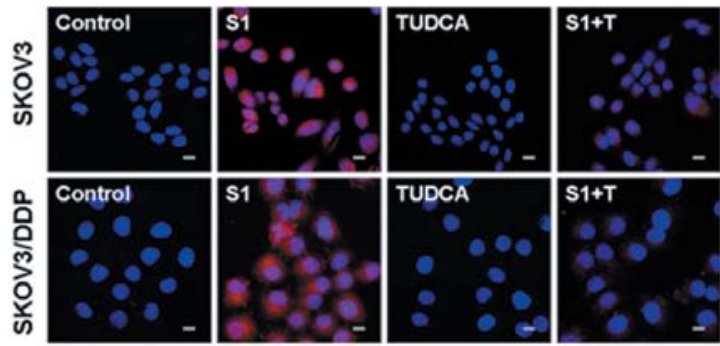

Figure 2. S1 induces ER stress in SKOV3 and SKOV3/DDP cells. (A) Cells were treated with $10 \mu \mathrm{M}$ S1 for $0,4,8$ or $12 \mathrm{~h}$. The distribution of PDI in the cytoplasm was observed by confocal microscopy (bar, $10 \mu \mathrm{m}$ ). (B) Western blot analysis for the expression of PDI and Grp78 in SKOV3 and SKOV3/DDP cells after treatment with $10 \mu \mathrm{M}$ S1. (C) Quantification of the PDI and Grp78 protein levels. Data are presented as means \pm SD $(\mathrm{n}=3)$. . $\mathrm{P}<0.05$ vs. control. (D) Cells were treated with $10 \mu \mathrm{M} \mathrm{S} 1$ or S1 combined with $0.5 \mathrm{mM}$ TUDCA for $12 \mathrm{~h}$.

These findings indicate that the $\mathrm{S} 1$ induces ER stress in both SKOV3 and SKOV3/DDP cells.

S1-induced ER stress-associated apoptosis in SKOV3 and SKOV3/DDP cells. To determine the relevance of ER stress to S1-induced apoptosis, we investigated whether ER-resident caspases are activated by S1. Caspase- 4 is an ER-resident caspase, activated in response to ER stress and is required for ER stress-induced apoptosis (similar to caspase-12 in murine cells) (25-27). As show in Fig. 3A and B, cleaved caspase-4 
$\mathbf{A}$

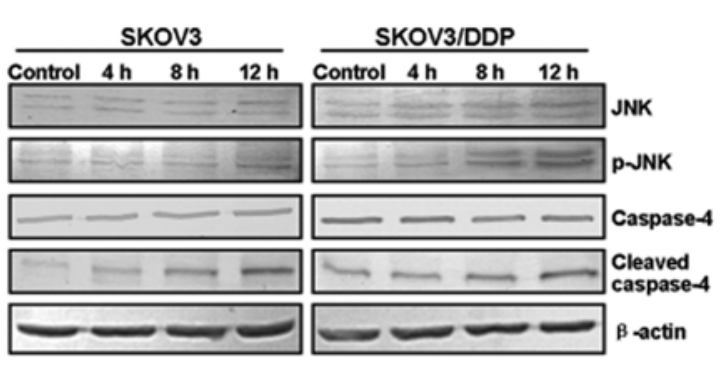

C
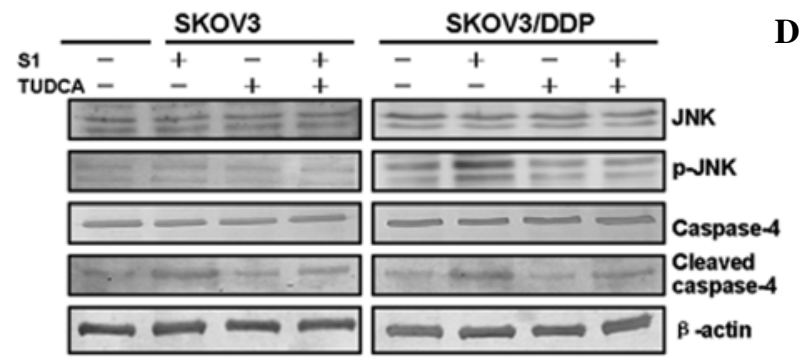

B

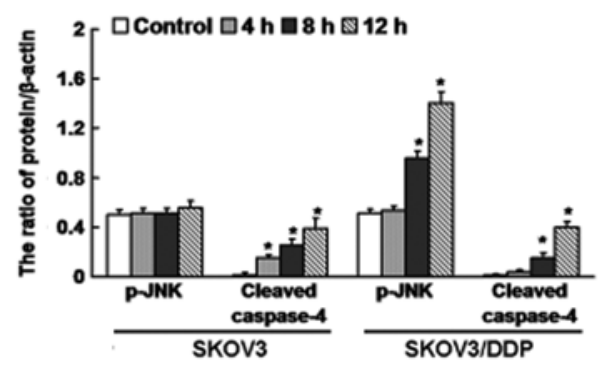

D

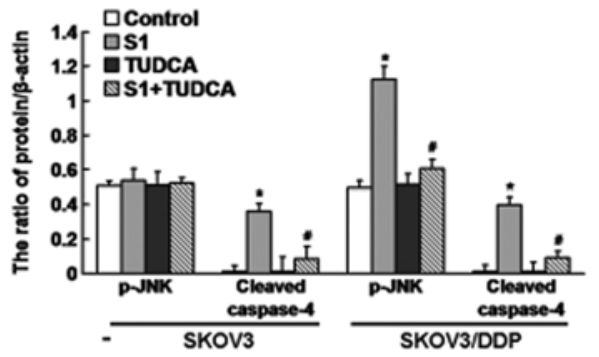

SKOV3

$\mathbf{E}$

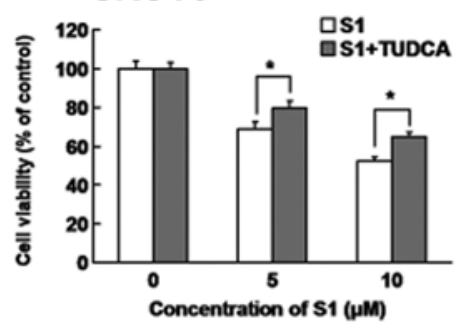

SKOV3/DDP

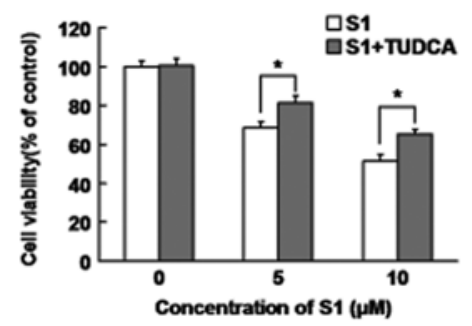

Figure 3. TUDCA decreases S1-induced ER stress-associated apoptosis in SKOV3 and SKOV3/DDP cells. (A) Western blot analysis for the expression of caspase-4, cleaved caspase-4, JNK, and p-JNK in both cell lines treated with $10 \mu \mathrm{M} \mathrm{S1.} \mathrm{(B)} \mathrm{Quantification} \mathrm{of} \mathrm{the} \mathrm{ER} \mathrm{stress-related} \mathrm{apoptotic} \mathrm{protein} \mathrm{levels.}$ Data are presented as means $\pm \mathrm{SD}(\mathrm{n}=3)$. ${ }^{*} \mathrm{P}<0.05$ vs. control. (C) Western blot analysis for the expression of caspase-4, cleaved caspase-4, JNK, and p-JNK in SKOV3 and SKOV3/DDP cells treated with S1 $(10 \mu \mathrm{M})$ and/or TUDCA $(0.5 \mathrm{mM})$ for $12 \mathrm{~h}$. (D) Quantification of the ER stress-related apoptotic protein levels. Data are presented as means $\pm \mathrm{SD}(\mathrm{n}=3)$. ${ }^{*} \mathrm{P}<0.05$ vs. control. ${ }^{*} \mathrm{P}<0.05$ vs. S1. (E) SKOV3 and SKOV3/DDP cells were treated with $\mathrm{S} 1(5$ or $10 \mu \mathrm{M})$ and/ or TUDCA $(0.5 \mathrm{mM})$ for $12 \mathrm{~h}$. Cell viability was determined by the MTT assay. Data are presented as means $\pm \mathrm{SD}(\mathrm{n}=3)$. ${ }^{*} \mathrm{P}<0.05$.

was significantly increased in SKOV3 cells at $4 \mathrm{~h}$ following $\mathrm{S} 1$ treatment, compared with $8 \mathrm{~h}$ in SKOV3/DDP cells, and both types of cells showed significant increases at $12 \mathrm{~h}$. Many signaling pathways are involved in ER stress. Among them, the IRE1/JNK pathway is extremely important in regulating apoptosis and is closely related to the Bcl-2 family (28). Therefore, we examined the expression of JNK protein. The expression of p-JNK was increased in SKOV3/DDP cells, but not in SKOV3 cells (Fig. 3A and B). As shown in Fig. 3C and $\mathrm{D}$, cleaved caspase-4 was downregulated in both cell lines treated with S1 plus TUDCA, compared with cells treated with $\mathrm{S} 1$ alone for $12 \mathrm{~h}$, while $\mathrm{p}-\mathrm{JNK}$ was downregulated only in the SKOV3/DDP cells. MTT assays indicated that TUDCA treatment attenuated the cytotoxic effects of S1 in both SKOV3 and SKOV3/DDP cells (Fig. 3E).

These findings indicate that ER stress-associated apoptosis is involved in S1-induced apoptosis in both SKOV3 and SKOV3/DDP cells, and S1-induced ER stress is delayed in SKOV3/DDP cells.

S1 treatment activates autophagy in SKOV3/DDP cells. Previous reports have suggested that autophagy can be induced by S1 (20). Therefore, we used indirect fluorescence technology to detect the activation of autophagy. We observed significant puncta of LC3, a molecular marker of autophagy, in SKOV3/DDP cells following $\mathrm{S} 1$ treatment at 2, 4 and $8 \mathrm{~h}$, but did not observe this effect in SKOV3 cells (Fig. 4A). We detected the transformation of LC3-I to LC3-II and expression of Beclin-1 by western blot analysis. Similarly, the ratio of LC3-II/LC3-I and expression of Beclin-1 were increased in SKOV3/DDP cells at 2, 4 and $8 \mathrm{~h}$, but were not increased in SKOV3 cells (Fig. 4B and C).

We used the autophagy-specific inhibitor 3-methyladenine (3-MA) to inhibit the autophagy induced by $\mathrm{S} 1$ in SKOV3/DDP cells. Western blot analysis demonstrated that SKOV3/DDP cells treated with S1 plus 3-MA showed a low ratio of LC3-II/LC3-I and low expression of Beclin-1, compared with cells treated with S1 alone (Fig. 4D and E). Using confocal microscopy, fewer LC3 puncta were observed in the cells after $4 \mathrm{~h}$ of treatment with S1 plus 3-MA (Fig. 4F). These findings demonstrate that $\mathrm{S} 1$ activates autophagy in SKOV3/DDP cells at early time points, but there is no activation in SKOV3 cells.

Inhibition of autophagy increases S1-induced ER stress-associated apoptosis in SKOV3/DDP cells. The above-described 
A
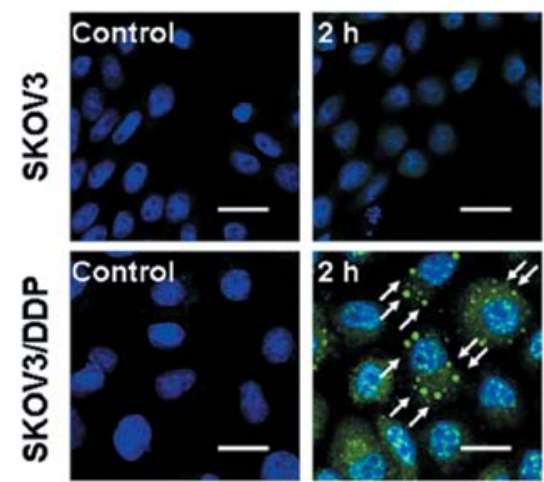
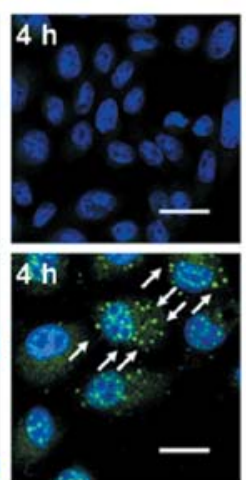
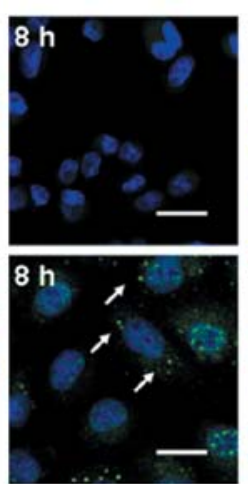

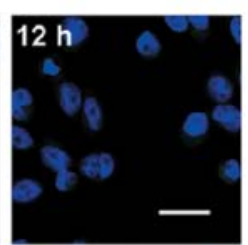

$12 \mathrm{~h}$

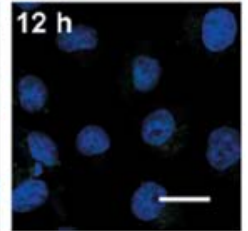

B

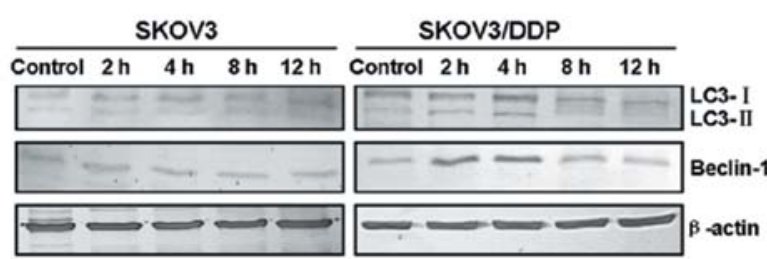

C

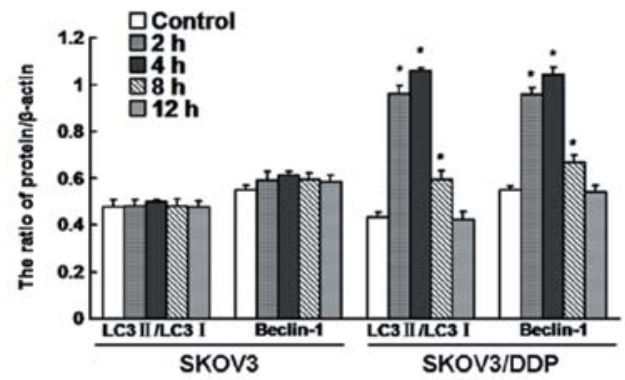

$\mathbf{F}$
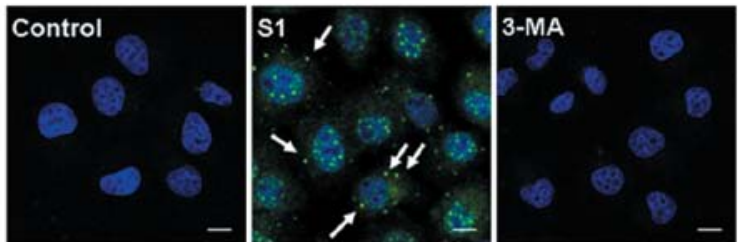

D

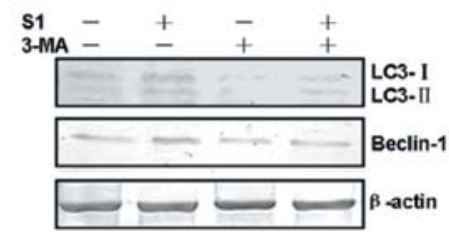

$\mathbf{E}$

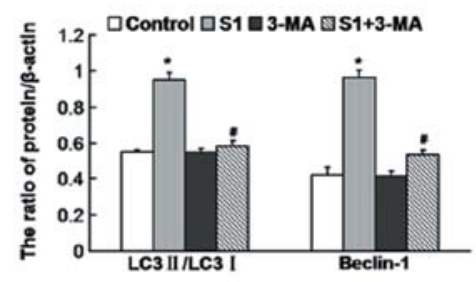

Figure 4. S1 treatment activates autophagy in SKOV3/DDP cells. (A) Confocal microscopy was used to detect the formation of LC3 puncta in SKOV3 and SKOV3/DDP cells treated with $10 \mu \mathrm{M} \mathrm{S} 1$ for $0,2,4,8$ or $12 \mathrm{~h}$. (bar, $20 \mu \mathrm{m}$; arrows, LC3 puncta). (B) Western blot analysis for the expression of C3-II/LC3-I and Beclin-1 in SKOV3 and SKOV3/DDP cells treated with $10 \mu \mathrm{M}$ S1. (C) Quantification of the LC3-II/LC3-I and Beclin-1 levels. Data are presented as means $\pm \mathrm{SD}(\mathrm{n}=3)$. ${ }^{*} \mathrm{P}<0.05$ vs. control. (D) Western blot analysis for the expression of LC3-II/LC3-I and Beclin-1 in SKOV3/DDP cells treated with $10 \mu \mathrm{M}$ S1 or S1 combined with 3-MA for $4 \mathrm{~h}$. (E) Quantification of the LC3-II/LC3-I and Beclin-1 levels. Data are presented as means \pm SD ( $=3$ ). "P<0.05 vs. control. ${ }^{\#} \mathrm{P}<0.05$ vs. S1. (F) Confocal microscopy was used to detect the formation of LC3 puncta in SKOV3/DDP cells treated with $10 \mu \mathrm{M}$ S1 or S1 combined with 3-MA for $4 \mathrm{~h}$ (bar, $10 \mu \mathrm{m}$; arrows, LC3 puncta).

findings showed that S1 treatment induced both an ER stress response and autophagy. Moreover, these events occurred in a defined time sequence in SKOV3/DDP cells, since we detected autophagy at early time points $(2$ and $4 \mathrm{~h})$ and ER stress-mediated apoptosis at later time points (8 and $12 \mathrm{~h})$. We subsequently further investigated the relationship of autophagy and ER stress-associated apoptosis following S1 treatment in SKOV3/DDP cells.

Using confocal microscopy and western blot analysis, we found that PDI was accumulated (Fig. 5A) and the expression levels of PDI and Grp78 were enhanced (Fig. 5B and C) after treatment with S1 plus 3-MA in SKOV3/DDP cells. To further confirm the role of autophagy in ER stress-mediated apoptosis, we detected the expression levels of p-JNK and cleaved caspase- 4 by western blot analysis. As shown in Fig. 5D and E, p-JNK and cleaved caspase-4 were upregulated in SKOV3/ DDP cells treated with S1 plus 3-MA, compared with cells treated with S1 alone for $4 \mathrm{~h}$. MTT assays indicated that 3-MA treatment enhanced the cytotoxic effect of S1 at early time points $(2$ and $4 \mathrm{~h}$ ), while a 12 -h treatment with 3 -MA combined with S1 had no significant toxic effect compared with S1 treatment alone (Fig. 5F).

These findings demonstrate that S1 leads to autophagy activation that attenuates ER stress-mediated apoptosis in SKOV3/DDP cells, and that inhibition of autophagy increases S1-induced ER stress-associated apoptosis at early time points. In the end, the activation of autophagy did not protect SKOV3/ DDP cells from S1-induced cell death. 

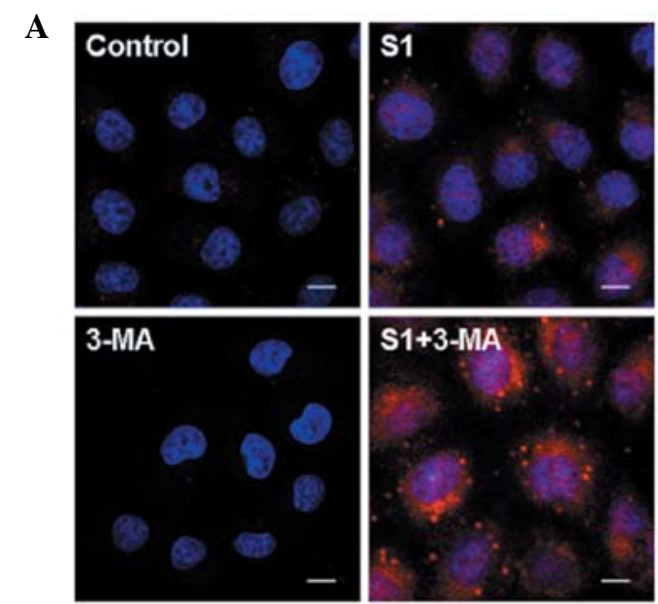

B

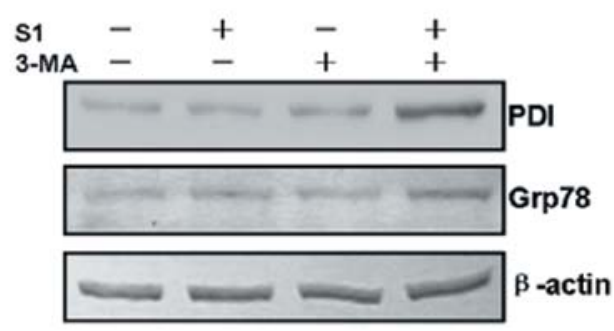

C

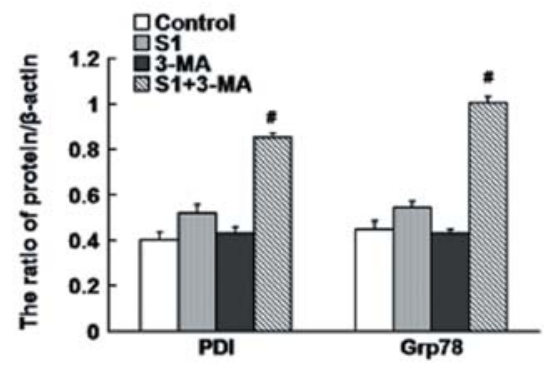

D

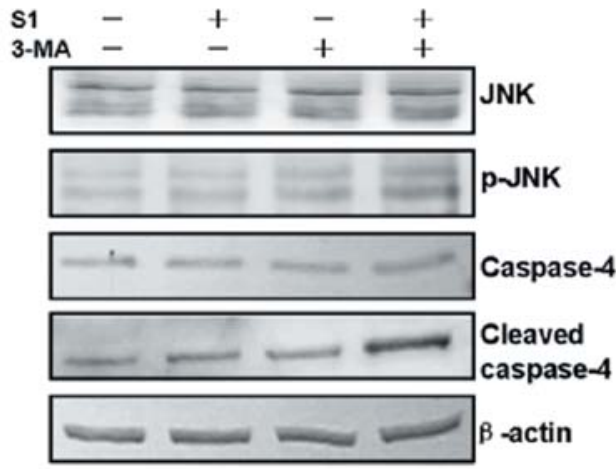

$\mathbf{E}$

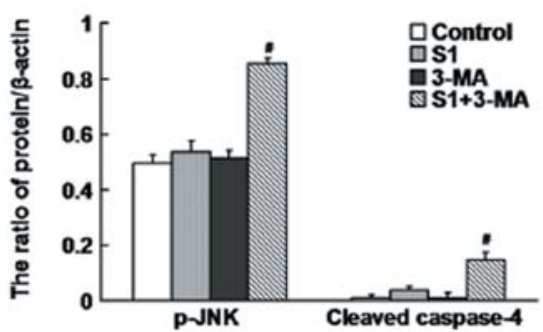

$\mathbf{F}$

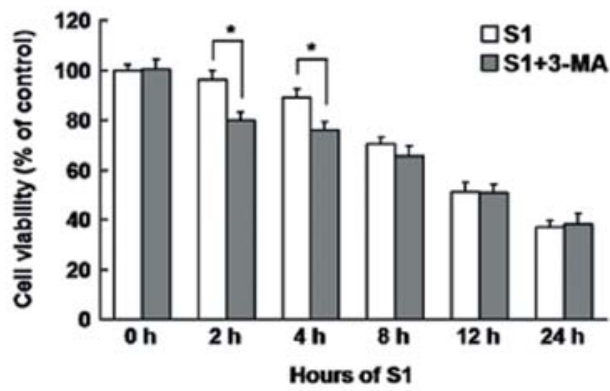

Figure 5. Autophagy attenuates S1-induced ER stress-mediated apoptosis in SKOV3/DDP cells. (A) Cells were treated with $10 \mu \mathrm{M} \mathrm{S1}$ and S1 combined with 3-MA for $4 \mathrm{~h}$. The distribution of PDI in the cytoplasm was observed by confocal microscopy. (B) Western blot analysis for the expression of PDI and Grp78 in SKOV3/DDP cells treated with $10 \mu \mathrm{M}$ S1. (C) Quantification of the PDI and Grp78 levels. Data are presented as means \pm SD (n=3). ${ }^{~} \mathrm{P}<0.05$ vs. S1. (D) Western blot analysis for the expression of JNK, p-JNK, caspase-4, and cleaved caspase-4 in SKOV3/DDP cells treated with $10 \mu \mathrm{M} \mathrm{S1}$ or S1 combined with 3-MA for $4 \mathrm{~h}$. (E) Quantification of the ER stress-related apoptotic protein levels. Data are presented as means $\pm \mathrm{SD}(\mathrm{n}=3) .{ }^{.} \mathrm{P}<0.05$ vs. S1. (F) SKOV3/DDP cells were treated with $\mathrm{S} 1(10 \mu \mathrm{M})$ and/or 3-MA $(10 \mathrm{mM})$ for $0,2,4,8,12$ or $24 \mathrm{~h}$. Cell viability was determined by the MTT assay. Data are presented as means $\pm \mathrm{SD}(\mathrm{n}=3)$. ${ }^{*} \mathrm{P}<0.05$.

\section{Discussion}

Currently, the resistance of ovarian cancer cells to chemotherapeutic-induced apoptosis is a difficult issue that remains to be solved in the treatment of ovarian cancer $(29,30)$. High Bcl-2 expression may be involved in the process of cancer cell resistance to chemotherapeutics (31-33). Therefore, treatments targeting Bcl-2 in tumors have been given a high priority. In the present study, treatment with the small-molecule BH3-only protein mimetic S1 for 12 or $24 \mathrm{~h}$ killed both cisplatin-sensitive SKOV 3 cells and cisplatin-resistant SKOV3/DDP cells, with no significant difference in the mortality of the cells following treatment for 12 or $24 \mathrm{~h}$, indicating that $\mathrm{S} 1$ effectively inhibited the survival of cisplatin-resistant human ovarian cancer cells through inhibition of $\mathrm{Bcl}-2$ expression.

$\mathrm{Bcl}-2$ is a crossover point of multiple signaling pathways, as the Bcl-2-specific inhibitor, S1, induces not only apoptosis via the mitochondrial pathway (17,19), but also ER stress (20). When cells receive low-level stimulation, the ER resists the stimulation by maintaining cell homeostasis (34). When cells are severely damaged, ER stress initiates a cell death program via the JNK, caspase-4, and GADD153 signaling pathways $(26,35)$. Our findings showed that $\mathrm{S} 1$ treatment induced elevated expression of PDI, Grp78 and caspase-4 in SKOV3 and SKOV3/DDP cells, suggesting that S1 may induce apoptosis of human ovarian cancer cells via the ER stress pathway. However, the apoptosis of SKOV3/DDP cells induced by ER stress occurred at a significantly later time point than that of SKOV3 cells. The ER stress-mediated apoptosis of SKOV3/DDP cells induced by S1 triggered JNK activation. After TUDCA-mediated inhibition of ER stress, JNK phosphorylation decreased, suggesting that $\mathrm{S} 1$ induced ER stress-associated apoptosis in SKOV3/DDP cells through activation of JNK and caspase-4. It was previously reported 
that JNK triggers apoptosis by mediating Bcl-2 phosphorylation (36). However, our findings showed that the activation of the JNK signaling pathway was mediated by the S1-induced ER stress pathway.

Importantly, the present study revealed a significant difference in the survival rates of SKOV3 and SKOV3/DDP cells following S1 treatment for short periods (2 and 4 h). Further analyses showed different levels of autophagy activation in the two types of cells. Following S1 treatment for 2, 4 or $8 \mathrm{~h}$, punctate aggregation of LC3 was observed, the ratio of LC3II/ LC3I was increased, and obvious autophagy was present in SKOV3/DDP cells, while no obvious punctate aggregation of LC3 was observed in SKOV3 cells. It was reported that autophagy activation mediates apoptosis in apoptosis-deficient cells, which is termed autophagic cell death $(37,38)$. However, when cells with normal apoptosis receive a specific stimulation, activation of autophagy protects cells by inhibiting apoptosis (39-43), and this protective autophagy is activated in a time-dependent manner (44), suggesting that autophagy activation may be involved in the survival and death of SKOV3/ DDP cells. Combined treatment with 3-MA and S1 reduced cell survival compared with $\mathrm{S} 1$ treatment alone, demonstrating that autophagy activation facilitated drug-resistant cell resistance to drug stimulation.

Recently, the roles of ER stress and autophagy in cells and their interaction have become a hot topic of research. Our findings showed that S1 treatment induced autophagy activation and ER stress-associated apoptosis in SKOV3/DDP cells. To assess the effect of the autophagy caused by S1 treatment on ER stress-associated apoptosis, 3-MA was used to inhibit autophagy, and significantly enhanced caspase- 4 activation and increased ER stress were observed. These observations indicate that $\mathrm{S} 1$ treatment-induced autophagy of SKOV3/DDP cells may be a resistant stress to the external environment. However, such protection by autophagy only functions within a short period. With prolonged ER stress, autophagy activation is attenuated, and its protection is diminished.

In summary, our findings showed that $\mathrm{S} 1$, an inhibitor of Bcl-2, effectively induced ER stress-associated apoptosis in both SKOV3 and SKOV3/DDP cells. Activation of autophagy within a short period provided protection for SKOV3/DDP cells and facilitated their resistance to stress. However, with prolongation of the S1 treatment, autophagy activation was attenuated and ER stress-mediated apoptosis played a leading role, effectively killing SKOV3/DDP cells. These results suggest that transient activation of autophagy is inadequate to resist S1-induced apoptosis, demonstrating that $\mathrm{S} 1$ inhibits the growth of human ovarian cancer SKVO3 and SKOV3/DDP cells, thereby effectively killing drug-resistant tumor cells.

\section{Acknowledgements}

This research was supported by the National Natural Science Foundation of China (nos. 81272876, 81141099, 81100808, and 81202552).

\section{References}

1. Karnak D and Xu L: Chemosensitization of prostate cancer by modulating Bcl-2 family proteins. Curr Drug Targets 11: 699-707, 2010.
2. Gul O, Basaga H and Kutuk O: Apoptotic blocks and chemotherapy resistance: strategies to identify Bcl-2 protein signatures. Brief Funct Genomic Proteomic 7: 27-34, 2008.

3. Liu JR, Opipari AW, Tan L, Jiang Y, Zhang Y, Tang H and Nuñez G: Dysfunctional apoptosome activation in ovarian cancer: implications for chemoresistance. Cancer Res 62: 924-931, 2002.

4. Klymenko T, Brandenburg M, Morrow C, Dive C and Makin G: The novel Bcl-2 inhibitor ABT-737 is more effective in hypoxia and is able to reverse hypoxia-induced drug resistance in neuroblastoma cells. Mol Cancer Ther 10: 2373-2383, 2011.

5. Zhang L, Ming L and Yu J: BH3 mimetics to improve cancer therapy: mechanisms and examples. Drug Resist Updat 10: 207-217, 2007.

6. Kang MH and Reynolds CP: Bcl-2 inhibitors: targeting mitochondrial apoptotic pathways in cancer therapy. Clin Cancer Res 15: 1126-1132, 2009.

7. Premkumar DR, Jane EP, DiDomenico JD, Vukmer NA, Agostino NR and Pollack IF: ABT-737 synergizes with bortezomib to induce apoptosis, mediated by Bid cleavage, Bax activation, and mitochondrial dysfunction in an Akt-dependent context in malignant human glioma cell lines. J Pharmacol Exp Ther 341: 859-872, 2012.

8. Wang X, Olberding KE, White $\mathrm{C}$ and $\mathrm{Li} \mathrm{C}$ : $\mathrm{Bcl}-2$ proteins regulate ER membrane permeability to luminal proteins during ER stress-induced apoptosis. Cell Death Differ 18: 38-47, 2010.

9. Bhavya BC, Indira D, Seervi M, Joseph J, Sobhan PK, Mathew KA, Varghese S and Santhoshkumar TR: Endoplasmic reticulum-targeted Bcl-2 inhibitable mitochondrial fragmentation initiates ER stress-induced cell death. Adv Exp Med Biol 749: 83-95, 2012

10. Dasmahapatra G, Lembersky D, Rahmani M, Kramer L, Friedberg J, Fisher RI, Dent P and Grant S: Bcl-2 antagonists interact synergistically with bortezomib in DLBCL cells in association with JNK activation and induction of ER stress. Cancer Biol Ther 8: 808-819, 2009.

11. Szegezdi E, Macdonald DC, Ní Chonghaile T, Gupta S and Samali A: Bcl-2 family on guard at the ER. Am J Physiol Cell Physiol 296: C941-C953, 2009.

12. Zhou F, Yang Y and Xing D: Bcl-2 and Bcl-xL play important roles in the crosstalk between autophagy and apoptosis. FEBS J 278: 403-413, 2010.

13. Marquez RT and Xu L: Bcl-2: Beclin 1 complex: multiple, mechanisms regulating autophagy/apoptosis toggle switch. Am J Cancer Res 2: 214-221, 2012.

14. Lian J, Wu X, He F, Karnak D, Tang W, Meng Y, Xiang D, Ji M, Lawrence TS and Xu L: A natural $\mathrm{BH} 3$ mimetic induces autophagy in apoptosis-resistant prostate cancer via modulating Bcl-2-Beclin1 interaction at endoplasmic reticulum. Cell Death Differ 18: 60-71, 2010.

15. Xu Y, Yu H, Qin H, Kang J, Yu C, Zhong J, Su J, Li H and Sun L: Inhibition of autophagy enhances cisplatin cytotoxicity through endoplasmic reticulum stress in human cervical cancer cells. Cancer Lett 314: 232-243, 2011.

16. Shi YH, Ding ZB, Zhou J, Hui B, Shi GM, Ke AW, Wang XY, Dai Z, Peng YF, Gu CY, Qiu SJ and Fan J: Targeting autophagy enhances sorafenib lethality for hepatocellular carcinoma via ER stress-related apoptosis. Autophagy 7: 1159-1172, 2011.

17. Zhang Z, Song T, Zhang T, Gao J, Wu G, An L and Du G: A novel BH3 mimetic S1 potently induces Bax/Bak-dependent apoptosis by targeting both Bcl-2 and Mcl-1. Int J Cancer 128: 1724-1735, 2010.

18. Zhang Z, Wu G, Gao J and Song T: Inclusion complex of a Bcl-2 inhibitor with cyclodextrin: characterization, cellular accumulation, and in vivo antitumor activity. Mol Pharm 7: 1348-1354, 2010.

19. Zhang Z, Wu G, Xie F, Song T and Chang X: 3-Thiomorpholin8-oxo-8H-acenaphtho[1,2-b]pyrrole-9-carbonitrile (S1) based molecules as potent, dual inhibitors of B-cell lymphoma 2 (Bcl-2) and myeloid cell leukemia sequence 1 (Mcl-1): structure-based design and structure-activity relationship studies. J Med Chem 54: 1101-1105, 2011.

20. Zhong JT, Xu Y, Yi HW, Su J, Yu HM, Xiang XY, Li XN, Zhang ZC and Sun LK: The BH3 mimetic S1 induces autophagy through ER stress and disruption of Bcl-2/Beclin 1 interaction in human glioma U251 cells. Cancer Lett 323: 180-187, 2012.

21. Muller C, Bandemer J, Vindis C, Camaré C, Mucher E, Guéraud F, Larroque-Cardoso P, Bernis C, Auge N, Salvayre R and Negre-Salvayre A: Protein Disulfide Isomerase Modification and Inhibition potentiates ER stress and apoptosis induced by oxidized low density lipoproteins. Antioxid Redox Signal 18: 731-742, 2013. 
22. Lee AS: The glucose-regulated proteins: stress induction and clinical applications. Trends Biochem Sci 26: 504-510, 2001.

23. Miller SD, Greene CM, McLean C, Lawless MW, Taggart CC O'Neill SJ and McElvaney NG: Tauroursodeoxycholic acid inhibits apoptosis induced by $\mathrm{Z}$ alpha-1 antitrypsin via inhibition of bad. Hepatology 46: 496-503, 2007.

24. Zhang JY, Diao YF, Kim HR and Jin DI: Inhibition of endoplasmic reticulum stress improves mouse embryo development. PLoS One 7: e40433, 2012.

25. Nakagawa T, Zhu H, Morishima N, Li E, Xu J, Yankner BA and Yuan J: Caspase-12 mediates endoplasmic-reticulum-specific apoptosis and cytotoxicity by amyloid- $\beta$. Nature 403: 98-103, 2000.

26. Binet F, Chiasson S and Girard D: Evidence that endoplasmic reticulum (ER) stress and caspase-4 activation occur in human neutrophils. Biochem Biophys Res Commun 391: 18-23, 2009.

27. Mao ZG, Jiang CC, Yang F, Thorne RF, Hersey P and Zhang XD TRAIL-induced apoptosis of human melanoma cells involves activation of caspase-4. Apoptosis 15: 1211-1222, 2010.

28. Verfaillie T, Salazar M, Velasco G and Agostinis P: Linking ER stress to autophagy: potential implications for cancer therapy. Int J Cell Biol 2010: 930509, 2010.

29. Eliopoulos AG, Kerr DJ, Herod J, Hodgkins L, Krajewski S, Reed JC and Young LS: The control of apoptosis and drug resistance in ovarian cancer: influence of p53 and Bcl-2. Oncogene 11: 1217-1228, 1995.

30. Mano Y, Kikuchi Y, Yamamoto K, Kita T, Hirata J, Tode T, Ishii $\mathrm{K}$ and Nagata I: Bcl-2 as a predictor of chemosensitivity and prognosis in primary epithelial ovarian cancer. Eur J Cancer 35: 1214-1219, 1999.

31. van Delft MF and Huang DC: How the Bcl-2 family of proteins interact to regulate apoptosis. Cell Res 16: 203-213, 2006.

32. Simonian PL, Grillot DA and Nuñez G: Bcl-2 and Bcl-XL can differentially block chemotherapy-induced cell death. Blood 90 : 1208-1216, 1997.

33. Reed JC, Miyashita T, Takayama S, Wang HG, Sato T, Krajewski S, Aimé-Sempé C, Bodrug S, Kitada S and Hanada M: BCL-2 family proteins: regulators of cell death involved in the pathogenesis of cancer and resistance to therapy. J Cell Biochem 60: 23-32, 1996.
34. Schönthal AH: Endoplasmic reticulum stress and autophagy as targets for cancer therapy. Cancer Lett 275: 163-169, 2009.

35. Schönthal AH: Pharmacological targeting of endoplasmic reticulum stress signaling in cancer. Biochem Pharmacol 85: 653-666, 2013.

36. Zhang YX, Kong CZ, Wang LH, Li JY, Liu XK, Xu B, Xu CL and Sun YH: Ursolic acid overcomes Bcl-2-mediated resistance to apoptosis in prostate cancer cells involving activation of JNK-induced Bcl-2 phosphorylation and degradation. J Cell Biochem 109: 764-777, 2010.

37. Shimizu S, Konishi A, Nishida Y, Mizuta T, Nishina $H$, Yamamoto A and Tsujimoto Y: Involvement of JNK in the regulation of autophagic cell death. Oncogene 29: 2070-2082, 2010.

38. Ouyang L, Shi Z, Zhao S, Wang FT, Zhou TT, Liu B and Bao JK: Programmed cell death pathways in cancer: a review of apoptosis, autophagy and programmed necrosis. Cell Prolif 45: 487-498, 2012

39. Yu H, Su J, Xu Y, Kang J, Li H, Zhang L, Yi H, Xiang X, Liu F and Sun L: p62/SQSTM1 involved in cisplatin resistance in human ovarian cancer cells by clearing ubiquitinated proteins. Eur J Cancer 47: 1585-1594, 2011.

40. Sun WL, Chen J, Wang YP and Zheng H: Autophagy protects breast cancer cells from epirubicin-induced apoptosis and facilitates epirubicin-resistance development. Autophagy 7: 1035-1044, 2011.

41. Sirichanchuen B,Pengsuparp T and Chanvorachote P: Long-term cisplatin exposure impairs autophagy and causes cisplatin resistance in human lung cancer cells. Mol Cell Biochem 364: 11-18, 2012.

42. Chen $\mathrm{N}$ and Karantza V: Autophagy as a therapeutic target in cancer. Cancer Biol Ther 11: 157-168, 2011.

43. Suh DH, Kim MK, Kim HS, Chung HH and Song YS: Unfolded protein response to autophagy as a promising druggable target for anticancer therapy. Ann NY Acad Sci 1271: 20-32, 2012.

44. Zeng R, He J, Peng J, Chen Y, Yi S, Zhao F and Cui G: The timedependent autophagy protects against apoptosis with possible involvement of Sirtl protein in multiple myeloma under nutrient depletion. Ann Hematol 91: 407-417, 2011. 